\title{
A Nova Rota da Seda e o dilema de Xinjiang
}

\section{The New Silk Road and the Xinjiang dilemma}

\section{La Nueva Ruta de la Seda y el dilema de Xinjiang}

Diego Pautasso'

Tiago Soares Nogara²

Ana Paula Bernardo de Sousa ${ }^{3}$

Gaio Doria ${ }^{4}$

DOI: 10.5752/P.2317-773X.2021v9.n3.p25

Recebido em: 23 de setembro de 2020

Aprovado em: 30 de novembro de 2020

\section{RESUMO}

Para além da já reconhecida relevância da Nova Rota da Seda, ou Iniciativa do Cinturão e Rota (Belt and Road Initiative - BRI), para a estratégia de inserção internacional da China, sua plena implementação também dialoga incisivamente com a continuidade do processo de unificação e reorganização nacional do país. Analisando as questões pertinentes à região de Xinjiang, o presente artigo sustenta a noção de que a Nova Rota da Seda interage diretamente com o imperativo e os esforços securitários nacionais de estabilização das fronteiras e de diluição das ameaças separatistas, ao promover a continentalização do desenvolvimento chinês. Além do mais, é possível argumentar que essa região representa um enlace territorial do processo de integração eurasiática liderado pela China. $\mathrm{O}$ artigo se divide em três partes: primeiro, apresentamos os principais vetores da ascensão e implementação da Nova Rota da Seda; em seguida, abordamos o histórico das tensões entre o processo de reconstrução nacional chinesa e os movimentos separatistas de Xinjiang; por fim, analisamos como a Nova Rota da Seda interage com as estratégias de contenção aos movimentos separatistas e terroristas da região.

Palavras-chave: Nova Rota da Seda - Iniciativa do Cinturão e Rota - China Xinjiang - ETIM.

\section{AbSTRACT}

In addition to the already recognized relevance of the New Silk Road, or Belt and Road Initiative (BRI), for China's international insertion strategy, its full implementation also speaks incisively with the continuity of the country's national unification and reorganization process. Analyzing the issues relevant to the Xinjiang region, this article supports the notion that the New Silk Road interacts directly with the national security imperative and efforts to stabilize borders and dilute separatist threats, promoting the continentalization of Chinese development. In addition, it is possible to argue that this region represents a territorial
1. Doutor e mestre em Ciência Política pela Universidade Federal do Rio Grande do Sul (UFRGS). E-mail: dgpautasso@ gmail.com

\section{Doutorando em Ciência Política} na Universidade de São Paulo (USP). Mestre em Relações Internacionais pela Universidade de Brasília (UnB). E-mail: tiagosnogara@gmail.com

3. Especialista em Estratégia e Relações Internacionais Contemporâneas pela Universidade Federal do Rio Grande do Sul (UFRGS). E-mail: anapaulabs@ feevale.br

4. Doutor em Direito pela Renmin University of China. E-mail: gaiodoria@ gmail.com 
link in the Eurasian integration process led by China. The article is divided into three parts: in the first, we present the main vectors of the emergence and implementation of the New Silk Road; then, we examine the history of tensions between the Chinese national reconstruction process and the separatist movements in Xinjiang; finally, we analyze how the New Silk Road interacts with the containment strategies of separatist and terrorist movements in the region.

Keywords: New Silk Road - Belt and Road Initiative - China - Xinjiang - ETIM.

\section{RESUMEN}

Además de la relevancia ya reconocida de la Nueva Ruta de la Seda, o Iniciativa de la Franja y la Ruta (BRI), para la estrategia de inserción internacional de China, su implementación plena también habla de manera incisiva con la continuidad del proceso de unificación y reorganización nacional del país. Al analizar los temas relevantes para la región de Xinjiang, este artículo apoya la noción de que la Nueva Ruta de la Seda interactúa directamente con el imperativo de seguridad nacional y los esfuerzos para estabilizar las fronteras y diluir las amenazas separatistas, promoviendo la continentalización del desarrollo chino. Además, es posible argumentar que esta región representa un vínculo territorial en el proceso de integración euroasiático liderado por China. El artículo se divide en tres partes: en la primera, presentamos los principales vectores del surgimiento e implementación de la Nueva Ruta de la Seda; luego, examinamos la historia de las tensiones entre el proceso de reconstrucción nacional chino y los movimientos separatistas en Xinjiang; finalmente, analizamos cómo la Nueva Ruta de la Seda interactúa con las estrategias de contención de los movimientos separatistas y terroristas en la región.

Palabras clave: Nueva Ruta de la Seda - Iniciativa de la Franja y la Ruta - China Xinjiang - ETIM.

Introdução

Xi Jinping, líder da chamada quinta geração de lideranças chinesas, lançou, em 2013, o programa Silk Road Economic Belt And The Maritime Belt, também conhecido como Nova Rota da Seda ou Iniciativa do Cinturão e Rota (Belt and Road Initiative - BRI). Tal iniciativa nasceu para impulsionar projetos de construção de infraestrutura - transporte, comunicação e energia -, voltada inicialmente para promover a integração da Eurásia e regiões adjacentes. Uma alusão às antigas rotas comerciais que ligavam a China ao restante da Ásia, à África à e Europa. O objetivo anunciado era promover a conectividade dos três continentes mencionados e seus mares adjacentes, contemplando o desenvolvimento diversificado, independente, equilibrado e sustentável dos países participantes (CHINA, 2015). Desde então, a iniciativa ganhou dimensões cada vez mais globais e o discurso chinês tem enfatizado relações win-win e o modelo de desenvolvimento harmonioso, caracterizado como uma retórica alternativa ao processo de globalização neoliberal (YIWEL, 2016).

Uma das dimensões cruciais da Nova Rota da Seda diz respeito às questões securitárias de ordem político-territorial, principalmente aquelas vinculadas às províncias autônomas da China. A hipótese do presente artigo é, portanto, de que a Nova Rota da Seda é chave para a estabili- 
zação das fronteiras e de diluição ameaças separatistas (sobretudo Xinjiang, Tibete e Mongólia Interior), insufladas por forças estrangeiras, ao promover a continentalização do desenvolvimento chinês e a integração eurasiática. Mais do que isto, como diz Berlie (2020, p. 52), "Xinjiang é um pivô da nova história da Ásia Central e, por meio dela, a Nova Rota da Seda pode chegar a países distantes".

Nesse sentido, analisamos o papel da Região Autônoma de Xinjiang como um enlace territorial do processo de integração regional liderado pela China. Essa região turcófona islamita apresenta intentos separatistas, ilustrando a um só tempo um desafio e uma oportunidade para a integração territorial da China e de seu entorno centro-asiático. Na primeira parte, apresentamos os principais vetores da ascensão e implementação da Nova Rota da Seda; em seguida, abordamos o histórico das tensões entre o processo de reconstrução nacional chinesa e os movimentos separatistas de Xinjiang; por fim, analisamos como a Nova Rota da Seda interage com as estratégias de contenção aos movimentos separatistas e terroristas da região.

Uma visão panorâmica sobre a Nova Rota da Seda

O contato entre o Ocidente e Oriente é algo que perpassa os séculos, e, por quase dois mil anos, árabes, chineses, persas, turcos e europeus, dentre outros povos, puderam realizar trocas culturais e comerciais através de uma enorme rede de estradas e interconexões. Desde o século XVIII, as Rotas da Seda ligavam diferentes regiões da Eurásia e África à China Imperial, com intenso fluxo de comerciantes, mercenários e peregrinos; de culturas, etnias, religiões e conhecimentos; de animais e plantas para a produção rural, etc. Segundo Samir Amin (1996), a Ásia foi considerada o centro dinâmico do mundo por milênios, e só perdeu este posto quando os europeus, que até então viviam na periferia deste sistema geopolítico, tiveram acesso a estes territórios por meio das Grandes Navegações. Em diversos textos de grandes nomes do pensamento europeu do século XIX sobre história, filosofia, direito, política, cultura; a Ásia foi apresentada como o centro de todas as nações do mundo e o ponto de partida da história mundial. Conforme as palavras do filósofo alemão Hegel (1999, p.93): "a história universal vai do leste ao oeste, pois a Europa é o fim da história universal, e a Ásia é o seu começo.".

Aliás, foi justamente a expansão européia sobre esse centro geopolítico do Oriente que concretizou essa mudança de paradigma e levou ao século de humilhações na China, da Primeira Guerra do Ópio, em 1839, até a Revolução Chinesa, em 1949. À Revolução coube a ampla tarefa de reconstrução nacional: integrar o país e recuperar territórios perdidos; reorganizar o Estado e suas instituições; e retomar o desenvolvimento nacional. Coube à política de Reformas de Abertura desencadeada nos anos 1970 sob a liderança de Deng Xiaoping desencadear um novo ciclo de desenvolvimento e integração territorial da China.

A aproximação sino-estadunidense na virada dos anos 1960-70, conformou aquilo que Pinto (2011) de um eixo combinando a globaliza- 
ção financeira estimulada por Washington com o embrionário milagre econômico chinês. Esse novo eixo sino-estadunidense de acumulação se desenvolveu por meio de sinérgicas complementaridades comerciais (ampliação da corrente de comércio), produtivas (articulação entre as empresas estadunidenses e chinesas na cadeia global de produção) e financeiras (reservas estrangeiras da China e títulos do Tesouro dos Estados Unidos). Assim, a China não apenas se aproveitou da dinâmica de acumulação da Ásia Oriental, como se converteu na 'terceira onda' de desenvolvimento dessa região (PAUTASSO, 2009) - com particularidades em relação à primeira, com epicentro no Japão, e à segunda, protagonizada pela ascensão dos Tigres Asiáticos.

$\mathrm{O}$ acelerado processo de desenvolvimento, ampliado desde as reformas, deu maior complexidade à inserção internacional da China, o que consequentemente demandou maior assertividade do país na arena global. Mas, sem sombra de dúvidas, o projeto mais ambicioso foi a Nova Rota da Seda, ou Iniciativa do Cinturão e Rota (Belt and Road Initiative - BRI), lançada em 2013 pelo governo chinês. O mecanismo propulsor da BRI é a construção de uma complexa rede de infraestrutura de transporte, comunicação e energia em toda região, em grande medida replicando o modelo gestado nas relações sino-africanas, de intercâmbio de obras por acesso recursos naturais - contribuindo para a segurança energética e alimentar da China.

Pode-se dizer que a Nova Rota da Seda encerra objetivos de curto, médio e longo alcance para Pequim: primeiramente, trata-se de um privilegiado mecanismo de exportação de serviços de engenharia, dando vasão à supercapacidade ociosa da economia chinesa, internacionalizando empresas, fomentando o comércio regional e, consequentemente, a demanda externa; em segundo lugar, impulsiona, dentre outras dimensões, a integração eurasiática, impulsionando a recriação do sistema sinocêntrico; por fim, reafirma a ascensão da liderança chinesa, a partir de um modelo de desenvolvimento e integração que representa o embrião de um projeto chinês de globalização - alternativo, por sua vez, à globalização neoliberal irradiada desde Washington (PAUTASSO; UNGARETTI, 2017). Além do mais, promove a continentalização do desenvolvimento chinês, integrando e estabilizando regiões de minorias, sobretudo Xinjiang, Tibete e Mongólia Interior.

Dessa forma, a BRI busca uma integração regional em moldes distintos. Ao invés de blocos econômicos com complexas amarras institucionais ou arranjos multilaterais, a iniciativa chinesa busca a linha de menor resistência. Ou seja, mobiliza sua capacidade em engenharia e financiamento, enquanto contribui para solucionar problemas infraestruturais de países periféricos. Como lembra Fallon (2015), a China recupera uma tradição, a da realização de projetos com megaestruturas, exemplificados pela Grande Muralha e o Grande Canal, ao passo que recupera sua condição de Império do Meio na região com a recriação de um novo sistema sinocêntrico. 


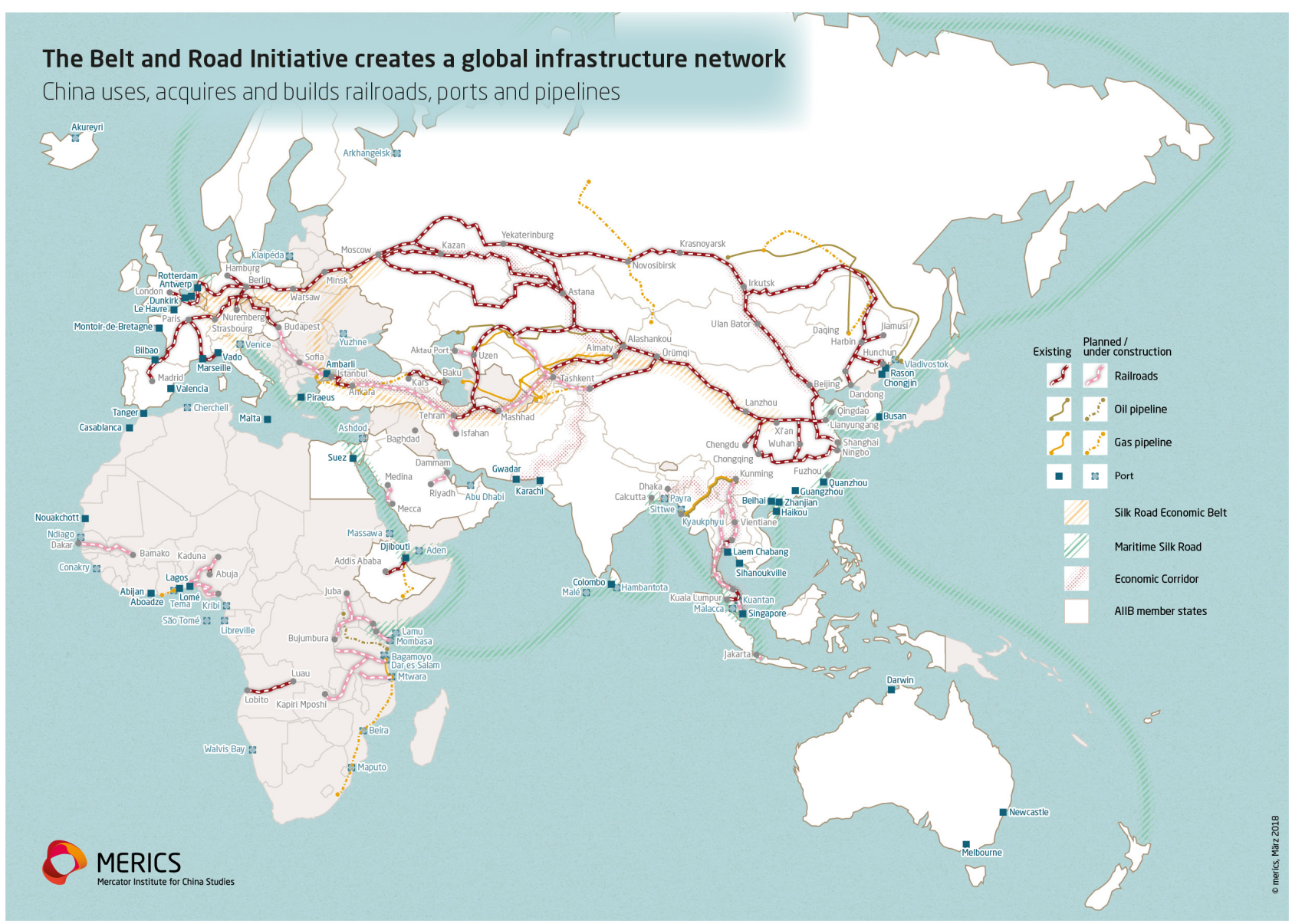

Fonte: Mercator Institute for China Studies (2018).

Em seu $13^{\circ}$ Plano Quinquenal ${ }^{5}$, de 2016, o governo chinês detalhou os objetivos a serem atingidos pela BRI. Incluía aumentar o comércio e o investimento regional; melhorar os mecanismos de cooperação multilateral; aprimorar a conectividade de infraestrutura; ampliar os fluxos de pessoas e capitais; impulsionar os mecanismos de cooperação financeira para o desenvolvimento, como o Banco Asiático de Investimento em Infraestrutura e o Novo Banco de Desenvolvimento e o Fundo da Rota da Seda; trabalhar para elevar Xinjiang à condição de região central do Cinturão Econômico da Rota da Seda, e Fujian ao principal ponto de contato da Rota Marítima da Seda; e promover cooperação nas áreas de educação, ciência, tecnologia, cultura, esportes, turismo, proteção ambiental e assistência médica.

E para dar consequência e articulação política da Nova Rota da Seda, o governo chinês estabeleceu um fórum bianual, inaugurado em 2017 e replicando bianualmente em 2019. Através do vetor infraestrutural, a china busca impulsionar o comércio e os investimento com os outros 65 países, responsáveis por mais de $30 \%$ do PIB global, $62 \%$ da população e $75 \%$ das reservas de energia conhecidas. Os dados oficiais dão conta de que o volume total de comércio entre a China e os países e regiões envolvidos na BRI excedeu US\$ 6 trilhões de dólares entre 2013 e $2018^{6}$.

A partir da ênfase da diplomacia chinesa no desenvolvimento compartilhado pela via do diálogo, a China assinou, até novembro de 2019,
5. Ver íntegra do documento, disponível em: https://en.ndrc.gov. cn/policyrelease_8233/201612/ P020191101482242850325.pdf
6. Ver reportagem, disponível em: https://www.beltandroad. news/2019/04/20/belt-road-countries-trade-exceeds-6-trillion-from-2013-to-2018/ 
7. Ver agência reportagem da Xinhua “China signs 197 B\&R cooperation documents with 137 countries, 30 international organizations", disponível em: http://www.xinhuanet.com/english/ 2019-11/15/c_138558369.htm
197 acordos de cooperação, com 137 países e 30 organizações internacionais, incluindo mais de dez agências da Organização das Nações Unidas (ONU) e a Agenda 2030 das Nações Unidas para o Desenvolvimento Sustentável. Nesse contexto, o governo chinês emitiu o Plano de Ação para a Conectividade Padrão do Cinturão e Rota e assinou mais de 80 documentos-quadro de cooperação para padronização com cerca de 50 países e regiões ${ }^{7}$. Também emitiu os Princípios Orientadores sobre o Financiamento do Desenvolvimento do Cinturão e Rota e a Sustentabilidade da Dívida - uma das críticas recorrentes à iniciativa de Pequim.

Em suma, a Nova Rota da Seda precisa ser compreendida como parte da reconstrução nacional chinesa e de sua projeção global de poder. Uma reconstrução que, depois de superados os percalços iniciais da revolução e encaminhado o projeto de desenvolvimento nacional, recupera tradições milenares. Internamente, deve-se observar a recuperação do confucionismo, da relação simbiótica entre mercado e planejamento e da capacidade de planejamento do aparelho estatal, característico do mandarinato. Internacionalmente, a China busca reconstituir o sistema sinocêntrico (PAUTASSO, 2011), recriando sua liderança sobre a Ásia. Se a Nova Rota da Seda representa o amálgama dessas duas dimensões, Xinjiang é seu enlace territorial.

A reconstrução nacional chinesa e ascensão do separatismo em Xinjiang

O ponto de partida é reconhecer que a China é um estado multiétnico desde a conformação de seu primeiro império, quando o nascente Império Qin (221-206 a.C.) pôs fim ao período dos Reinos Combatentes. Historicamente, as autoridades centrais das dinastias adotavam uma política de "governo por costume" para contemplar as minorias étnicas, garantindo a preservação de seus próprios sistemas sociais e culturais. Apesar das sucessões dinásticas, crises e alterações das fronteiras imperiais, o Império do Meio sempre exerceu esse efeito gravitacional sobre diversas formações sociais e culturais. Como destaca Visentini (2011, p. 23), cavaleiros mongóis, oficiais manchus, sacerdotes tibetanos e comerciantes uigures fizeram parte das dinastias chinesas e, eventualmente, à frente do Império. Aliás, de 1279 a 1378, a China foi governada por dinastia mongol e de 1644 a 1911 por dinastia manchu - o que representaria, considerando do declínio da Idade Média até as vésperas da I Guerra Mundial, 58\% do período (LOSURDO, 2012, p. 247). Ao invés de expansionismo han, o que houve foram sucessões dinásticas, historicamente conturbadas, com profundas alterações fronteiriças, cujo período do século de humilhações levou a amputações territoriais provocados por invasões e agressões estrangeiras, incluindo Tibete, Xinjiang, Manchúria (inclusive com estado fantoche japonês), além de perdas da Mongólia Exterior, Taiwan, Hong Kong e Macau.

Como pode-se perceber, Xinjiang possui parte da população com uma matriz étnica turca, proveniente da Ásia Central no século VII e islamizada por volta do século X. A região experimentou um período de relativa independência e isolamento a partir da Guerra do Ópio (1839), se tornan- 
do província apenas em 1884 ao fixar sua fronteira ocidental com a Rússia. Com o colapso da Dinastia Qing e a pulverização de autoridades políticas no território chinês, Xinjiang passou a ser dirigido por lideranças militares autônomas, que transitaram entre alianças com a União Soviética, primeiramente, e com o Kuomintang, num segundo momento, até serem derrotadas pelos comunistas em setembro de 1949, na esteira dos acontecimentos da revolução dirigida pelo Partido Comunista da China (PCCh).

Como a revolução teve caráter antifeudal e anti-imperialista, o imperativo imediato foi o da reconstrução nacional, incluindo a centralização política e o controle da unidade territorial. Num primeiro momento, a República Popular da China se autodenominou como um Estado multinacional. À beira da fragmentação do território, o governo emitiu, ainda em 1952, uma medida para concertação política, o Esboço para a Implementação da Autonomia Regional das Minorias Étnicas. Em 1954, o Congresso Nacional do Povo aprovou o sistema de autonomia regional para as minorias étnicas na Constituição da República Popular da China. Nesse contexto, foram estabelecidas as regiões autônomas, sendo a primeira a da Mongólia Interior, ainda em 1947, seguida pela Região Autônoma Uigur de Xinjiang (Xinjiang Uighur Autonomous Region - XUAR), em 1955, as de Guangxi e Ningxia, em 1958, e do Tibete, em 1965.

Apesar dessas medidas institucionais, a política do governo central foi de perseguição aos eventuais focos de poder paralelo, incluindo de minorias étnicas e religiosas, com a posterior Revolução Cultural agudizando esta tendência (MILLWARD, 2007). Ademais, ruptura Sino-Soviética fortaleceu o controle do governo chinês sobre a região, pois o isolamento internacional recrudesceu as preocupações com as questões securitárias nacionais, dados os laços consanguíneos entre os povos localizados na fronteira e que atravessa a Ásia Central até a Turquia. Com o colapso da União das Repúblicas Socialistas Soviéticas (URSS), os grupos fundamentalistas islâmicos apoiados pelos Estados Unidos e o Paquistão para conter os soviéticos no Afeganistão se expandiram pela Ásia Central.

A partir da década de 1990 foi criada uma série de organizações políticas e não-governamentais alinhada às reivindicações separatistas em Xinjiang. Dentre elas, destaca-se o East Turkistan Islamic Movement (ETIM), formado em 1990 sob o patrocínio da CIA, e desde 2002 é classificado oficialmente pela ONU como uma organização terrorista vinculada à Al Qaeda. Nesse sentido, o Ministério da Segurança da China também classificou o East Turkistan Liberation Organization (ETLO), o East Turkistan Information Center (ETIC) e o World Uygur Youth Congress (WUYC) como terroristas. Junto da International Uyghur Human Rights and Democracy Foundation e do World Uyghur Congress, o WUYC recebeu consideráveis patrocínios da US National Endowment of Democracy (NED) - organização internacional originariamente financiada pelo Congresso dos Estados Unidos, e vinculada à Soros Foundation na promoção de operações de desestabilização política desde a década de 1990, quando atuaram conjuntamente nos eventos concernentes ao desmembramento da Iugoslávia (BANDEIRA, 2014).

Aliás, o que ainda pauta boa parte das análises é um relatório intitulado ‘O Projeto Xinjiang' escrito pelo ex-oficial sênior da CIA Graham 
8. Ver detalhes acerca da formação do ETIM, disponível em: https://21stcenturywire.com/2018/12/14/the-truth-behind-chinas-uyghur-problem/
E. Fuller em 1998 para a Rand Corporation e revisado em 2003 sob o título The Xinjiang problem ${ }^{8}$. Noutro livro, intitulado Fire on the Water: China, America, and the Future of the Pacific, tipicamente do establishment político-militar, resta claro que guerras irregulares, não convencionais, operações midiáticas, ações encobertas voltadas a gerar desordens, jogar uma nacionalidade contra a outra, dividir e cooptar parte do aparelho estatal, para "provocar instabilidade por exemplo no Tibete e Xinjiang" (HADDICK apud LOSURDO, 2018, p. 358).

A China não tardou em buscar respostas para tais dilemas. Assim, ainda em 2000 foi lançada pelo presidente Jiang Zemin a campanha do Desenvolvimento do Grande Oeste, visando estabelecer corredor comercial e energético conectando a China aos vizinhos da Ásia Central (CLARKE, 2016). Nesse mesmo sentido, a China foi impulsionou a criação em 2001 da Organização da Cooperação de Xangai (OCX) - junto à Rússia, Cazaquistão, Quirguistão, Uzbequistão e Tadjiquistão -, tendo como um de seus principais eixos o combate multilateral à proliferação de grupos extremistas na Ásia Central. A organização nasceu com a prioridade de combater os três males (separatismo, terrorismo e fundamentalismo), no contexto da Guerra Global ao Terror (GGT) desencadeada por Washington - um tanto problemática dado que esta não poderia avançar sem debelar o apoio de dois aliados do movimento jihadista, Arábia Saudita e Paquistão (COCKBURN, 2015).

No entanto, questões geoestratégicas mais amplas impediram que os Estados Unidos mantivessem uma postura de apoio ostensivo às movimentações separatistas de Xinjiang. $\mathrm{Na}$ esteira dos acontecimentos do 11 de setembro de 2001 e do apoio chinês à GGT, os Estados Unidos passaram a ensejar esforços em prol da inclusão do ETIM na lista de grupos terroristas reconhecidos pela ONU. As intervenções estadunidenses decorrentes da GGT modificaram o panorama de atuação do ETIM, que passou a enfrentar tropas paquistanesas e dos Estados Unidos, além das chinesas, no conjunto de países da Ásia Central. O grupo - que entre 1990 e 2001 havia cometido mais de 200 atos de terrorismo, especialmente contra civis e órgãos de Estado chineses - teve diversos integrantes capturados e levados à Guantánamo, além de ter seu líder, Abu-Muhammad al Turkestani, morto em 2003 (BANDEIRA, 2014).

Ainda assim, Anwar Yusuf Turani autoproclamou-se, em 2004, chefe do governo do Turquestão Oriental - sediado em Washington, ainda que sem reconhecimento pelo governo estadunidense -, evidenciando uma possível inflexão no cenário dos enfrentamentos (BANDEIRA, 2014). Essa inflexão tomaria forma perante os avanços da estratégia de Pequim de criar o Corredor Econômico China-Paquistão, integrando o porto de Gwadar, no Paquistão, à região de Xinjiang. Este projeto representava, para além de um arranjo de cooperação regional, um importante passo para o sucesso da estratégia chinesa de superação de possíveis obstruções de sua segurança energética.

Em 2009, um levante seria protagonizado em Urumqi, capital de Xinjiang, deixando 197 mortes e mais de 1.700 feridos e evidenciando uma nova etapa de internacionalização do conflito. Segundo o Departamento de Segurança Pública de Xinjiang, os métodos terroristas se tornaram 
cada vez mais violentos; em 1999, num esconderijo encontraram 5.000 granadas caseiras do grupo terrorista Kuresh, em 2006, 15.000 armas contrabandeadas do exterior foram apreendidas ${ }^{9}$. Diversos foram os atentados terroristas praticados por grupos afins às perspectivas separatistas entre 1990 a 2020, matando um grande número de pessoas inocentes e centenas de policiais. Além destes eventos ocorridos na capital de Xinjiang, Urumqi, em 2009, também ocorreram na Praça da Paz Celestial, em 2013, e na estação de trem de Kunming, em 2014. Os documentários Fighting terrorism in Xinjiang ${ }^{10}$, e A mão negra - ETIM e terrorismo em Xinjiang"1 , produzidos pela CGTN, abordam com excelência tais questões. Aliás, milhares destes terroristas se vincularam ao Estado Islâmico durante a guerra na Síria.

Segundo Fuller e Starr (2003, p. 46), os Estados Unidos têm preocupações sobre a natureza do futuro papel da China no cenário internacional e por isso Washington exerce pressão sobre Pequim através do através da Uyghur card e seu potencial desestabilizador. Trata-se de uma política voltada ao desmembramento da China, excluindo, além de Xinjiang, Mongólia Interior e Manchúria e Tibete - no último caso mobilizando uma suposta bandeira da não-violência como elemento para o Grande Jogo estadunidense na região (LOSURDO, 2012, p. 245-254). Além do mais, como destacaram Reed e Raschke (2010), os Estados Unidos assumem uma postura moderada perante o ETIM, na medida em que inserem o agrupamento nas listas-negras do terrorismo vinculadas ao financiamento e imigração, mas o mantém fora da lista de grupos terroristas estrangeiros reconhecidos pelo Departamento de Estado.

A questão intermitente de Xinjiang voltou à tona em 2020, quando as grandes agências de notícias internacionais, como a Reuters ${ }^{12}$, afirmaram que a ONU tem relatos sobre um contingente de cerca de 1 milhão de muçulmanos uigures em "campos de reeducação" na China. Contudo, não há nenhum documento do Alto Comissariado das Nações Unidas para os Direitos Humanos (Office of the High Commissioner for Human Rights - OHCHR $)^{13}$ sobre o assunto, mas sim relatos do grupo de ativistas Rede de Defensores dos Direitos Humanos da China (Chinese Human Rights Defenders - CHRD), sediado em Washington e patrocinado, entre outros, pela NED ${ }^{14}$. Apesar do frenesi na mídia ocidental, cerca de 54 países, dentre os quais muitos de maioria populacional muçulmana, defenderam oficialmente em uma conferência da ONU as medidas chinesas de combate ao extremismo terrorista na região ${ }^{15}$.

Nesse contexto o governo chinês tem estendido as políticas para as minorias étnicas. Com o documento Autonomia Regional para Minorias Étnicas na China (2005), do Gabinete de Informação do Conselho de Estado da República Popular da China, a China estabeleceu, em 2003, 155 áreas autônomas étnicas, somando ainda 30 prefeituras autônomas e 120 municípios autônomos. Quer dizer: além de usufruir dos mesmos direitos de outros órgãos estatais, possuem direito de formular regulamentos de autogoverno de modo a atender às condições específicas do grupo étnico, incluindo uso e desenvolvimento de seus idiomas, liberdade de crença religiosa e costumes, autonomia da formulação de políticas educacionais e culturais, etc ${ }^{16}$.
9. Ver documentário, disponível em: https://www.youtube.com/watch?v=BjgSOYRZqlo

10. Ver documentário, disponível em: https://www.youtube.com/watch?v=BjgSOYRZqlo

11. Ver documentário, disponível em: https://news.cgtn.com/news/2019-1207/The-black-hand-ETIM-and-terrorism-in-Xinjiang-MepKpOPAKA/index.html

12. Ver notícia original, disponível em: https://www.reuters.com/article/us-china-rights-un/u-n-says-it-has-credible-reports-that-china-holds-million-uighurs-in-secret-camps-idUSKBN1KV1SU

13. Ver relatório da ONU, disponível em: https://www.ohchr.org/EN/NewsEvents/Pages/DisplayNews.aspx?Newsl$\mathrm{D}=23452$ \&Lang $\mid \mathrm{D}=\mathrm{E}$

14. Ver notícia sobre financiamento do grupo ativista, disponível em: https:// thegrayzone.com/2018/08/23/un-did-not-report-china-internment-camps-uighur-muslims/

15. Ver reportagem do Global Times, disponível em: https://www.globaltimes. cn/content/1168522.shtml

16. Disponível em: http://www.gov. cn/english/official/2005-07/28/content_18127.htm 
17. Ver detalhes no site oficial do governo chinês, disponível em: http://www. china.org.cn/english/features/43608.htm
Embora a China contabilize 56 etnias, 91,64\% são chineses étnicos (han), 1,27\% de zhuangs, e todas as demais abaixo de $1 \%$, conforme o China Ethnic Statistical Yearbook 2016. Pode-se dizer que há uma região core habitada pela população han e circundada por outras regiões, incluindo Xinjiang, Tibete, Mongólia Interior, Manchúria e outras províncias menores. A região de Xinjiang é habitada por pouco mais de 20 milhões de habitantes, cerca de 1,4\% da população da China, distribuídos em 47 grupos étnicos, com aproximadamente $45 \%$ de uigures (turcófonos islâmicos), $41 \%$ de chineses han, $7 \%$ de cazaques, $7 \%$ de huis (chineses muçulmanos), além de outras minorias menos expressivas (mongóis, quirguizes, etc.). São 1,66 milhões de $\mathrm{km}^{2}$, representando 1/6 do território chinês e com cerca de $5,5 \mathrm{mil} \mathrm{km}$ de fronteira com outros países: com a Mongólia, ao nordeste; com a Rússia, o Cazaquistão, o Quirguistão e o Tajiquistão ao oeste; e com o Afeganistão, o Paquistão e a Índia ao sudoesteEssas unidades administrativas gozam de especificidades, de acordo com a Lei de Autonomia Étnica Regional ${ }^{17}$.

Figura 2 - Localização de Xinjiang

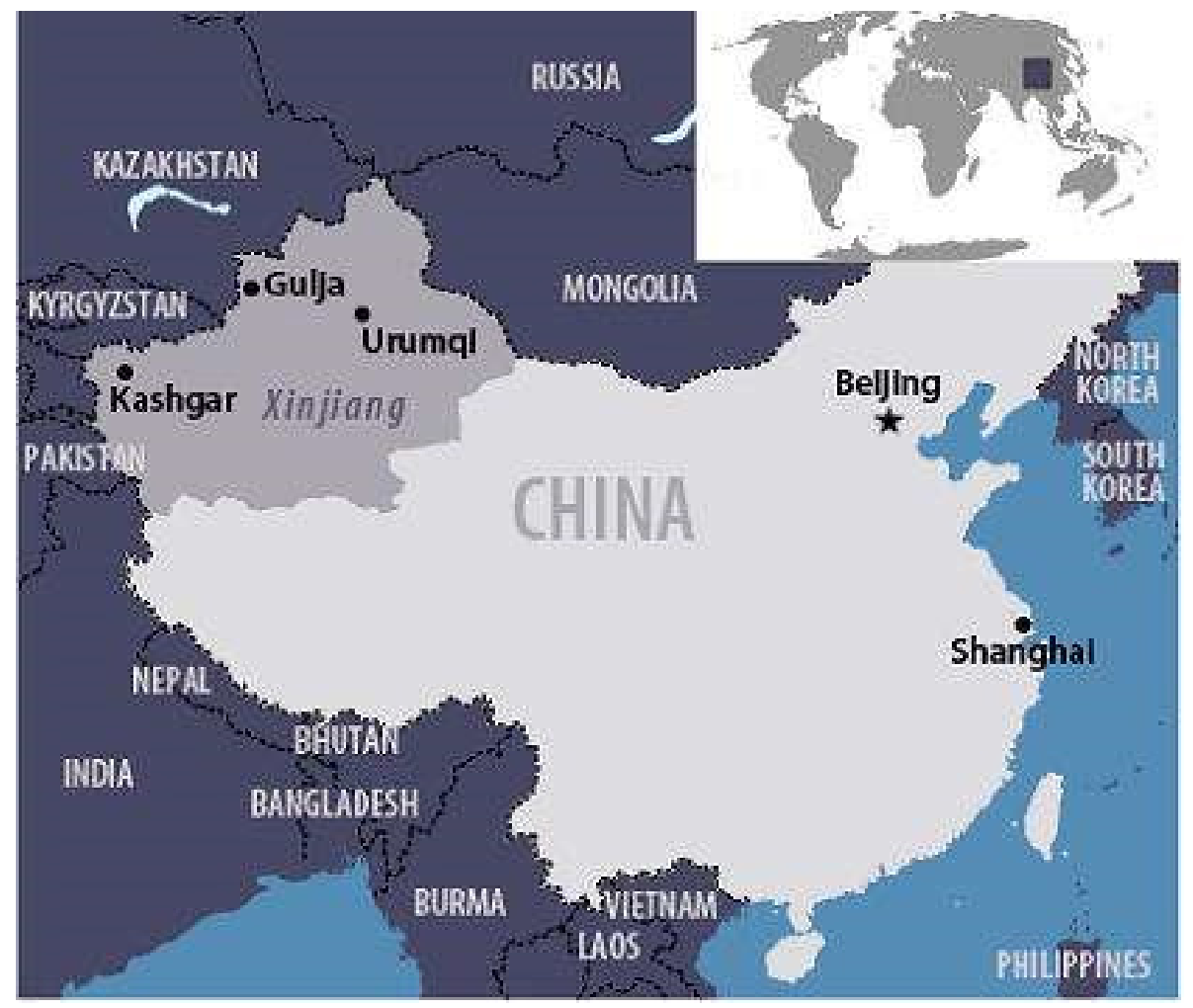

Fonte: Fevrier (2017).

No contexto da escalada das narrativas anti-chinesa, Pequim tem trabalhado para dirimir os intentos separatistas com maior ênfase no consentimento do que na coerção, distintamente dos primeiros momentos após a revolução. É nesse quadro, pois, que se enquadra o documento intitulado A luta contra o terrorismo e o extremismo e a proteção dos direitos humanos em Xinjiang ${ }^{18}$, combinando o combate implacável da influência de separatistas, extremistas religiosos e terroristas à busca de promoção de ainda mais direitos aos povos uigures. Além disso, o governo chinês 
tem buscado promover, por um lado, políticas de reconhecimento, como através da construção de mais de 35.000 mesquitas - muito mais que as 2.300 na França, 2.106 nos Estados Unidos ou 1.600 na Grã-Bretanha, que mesmo numa base per capita daria cerca de três vezes mais mesquitas no país oriental. E, por outro, políticas distributivas via desenvolvimento. Para se ter uma ideia, o Escritório de Informação do Conselho de Estado (SCIO) divulgou um relatório apresentando o desenvolvimento econômico e social nos últimos 70 anos na Região Autônoma Uigur de Xinjiang, destacando 1) o aumento do PIB de 791 milhões de yuans em 1952 para 1,22 trilhão de yuans em 2018, um crescimento médio anual de $8,3 \% ; 2$ ) mais de 2,31 milhões de pessoas foram retiradas da pobreza entre 2014 a 2018 ; 3) e o PIB per capita aumentou 37,7 vezes com base no ajuste da inflação para 49.475 yuans $^{19}$. Além do mais, a Associação Mundial de Medicina Natural declarou Xinjiang como uma das quatro regiões do mundo com maior média de longevidade, tendo o maior número de pessoas centenárias por milhão de pessoas da China (LIANGQI, 2012).

Apesar do desenvolvimento econômico, o desafio para a estabilidade local segue sendo as tensões inter-étnicas. Por vezes, ações afirmativas como educação bilíngüe aumenta convívio e tensões; os funcionários han responsáveis pela execução de obras eventualmente não tem familiaridade com a situação local; e a própria securitização da região, com controles mais rígidos, gera conflitos (ZHANG; MCGHEE, 2014). Ademais, as desigualdades sociais provocam ressentimento em uigures, enquanto muitos se sentem privados de reconhecimento em termos políticos, culturais e religiosos. Para tanto, Pequim tem buscado combinar a promoção do desenvolvimento com a repressão aos focos de desestabilização (HAO; LIU, 2012). Isto é, em meio ao mais notável processo de modernização e mobilização social, o governo chinês tem de lidar com o imperativo de superar clivagens sociais, regionais e étnico-religiosas entrelaçadas, frequentemente fomentada por atores estrangeiros.

A Nova Rota da Seda e a estratégia de contenção do separatismo

Em razão de sua posição estratégica, Xinjiang é uma das regiões que mais tem recebido investimentos oriundos da Nova Rota da Seda. Não obstante, em março de 2015, a Comissão Nacional de Desenvolvimento e Reforma emitiu um documento intitulado Visão e Ações para Promover a Construção Conjunta da Faixa Económica da Rota da Seda e da Rota Marítima da Seda do Século XXI onde estabelece o quadro político para o desenvolvimento da iniciativa. No tocante aos papéis regionais dentro da BRI, o documento afirma que deve-se "tirar proveito da vantagem geográfica particular e do papel da Região Autónoma Uigur de Xinjiang como uma janela importante para se abrir ao Oeste, aprofundar o intercâmbio e a cooperação com os países da Ásia Central, Ásia Meridional e Ásia Ocidental, formar um importante ponto de conexão para os transportes e comunicações, um centro de comércio, logística, cultura, ciência e educação, criar uma zona econômica central na Faixa Econômica da Rota da Seda." (CHINA, 2015, p. 1). A XUAR representa o território que entrelaça i) o comércio fronteiriço com os países da Ásia Central, ii) o
19. Ver reportagem da CGTN, disponível em: https://news.cgtn.com/news/201907-30/How-Xinjiang-s-economy-and-society-developed-in-the-last-70-years-IKcPHfKLGU/index.html 
acesso direto aos recursos energéticos e matérias primas e iii) os desafios securitários daquela região.

Através dos investimentos em infraestrutura, a Nova Rota da Seda tem gerado empregos e desenvolvimento no oeste chinês (HAYES, 2015). Para 2017, por exemplo, o orçamento foi estipulado em 170 bilhões de yuans destinados a construção de rodovias, 8,1 bilhões para as ferrovias e 4,8 bilhões para a aviação civil, com os dois últimos tiveram aumentando 50\% do orçamento em relação ao de 2016 (WEIHUA; JIA, 2017) - um montante total de $\$ 27,2$ bilhões de dólares. Nos últimos anos, a escala da rede de infraestrutura de transporte de Xinjiang aumentou consideravelmente. Até o momento, Xinjiang conta com uma malha ferroviária de mais de 6.200 quilômetros, com 21 aeroportos de transporte civil e com vias expressas que ultrapassam 5.200 quilômetros.

Com efeito, as autoridades da província autônoma já estabeleceram como prioridade a função logística de Xinjiang dentro da Nova Rota da Seda, dada sua posição de enlace territorial entre o leste da China e a Ásia Central. Atendendo à estratégia de desenvolvimento coordenado regional, o Planejamento da Rede de Transporte Abrangente da Região Autônoma de Xinjiang Uygur (2021-2050) vem sendo elaborado em conjunto com o governo central. Segundo Wang Xinlin (2020), apesar dos gargalos em termos de infraestrutura, mas é nítido o objetivo de converter Xinjiang na região de interconexão territorial com o exterior em área central da BRI.

A ideia de Xinjiang como central para a Nova Rota da Seda tem se tornado mais evidente (YAN, 2016). Trata-se de um enlace territorial, da conectividade através da Ásia Central até a Europa, implicando em redução de tempo e custo no acesso aos mercados estrangeiros. Até então, a forma mais prática de fazê-lo era através do Estreito de Malaca, no Mar da China, levando aproximadamente de 20 a 40 dias para chegar a seu destino (Europa, por exemplo). A rota via Xinjiang permite que os produtos chineses alcancem o mesmo destino em apenas 16 dias, através da construção de uma ferrovia de alta velocidade (11.179 quilômetros de extensão) que corta a Ásia Central, passando por Ürümqi, capital da XUAR, depois pela Ásia Central, Rússia por grande extensão da Europa, até chegar à Alemanha. 
Figura 3 - Ferrovia entre Chongqing e Duisburg

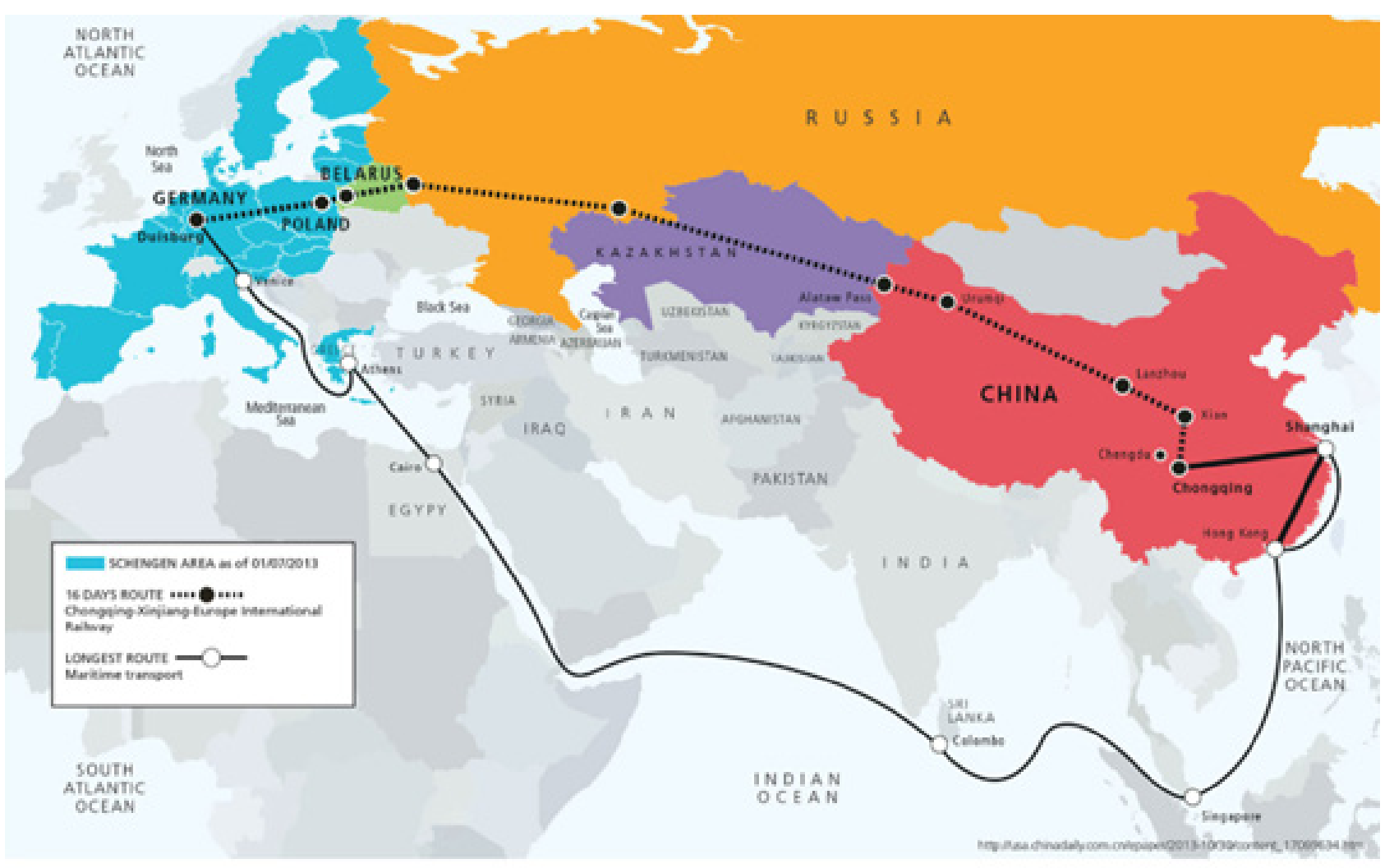

Fonte: Chen e Mardeusz (2015)

Para além das vias de acesso aos mercados euroasiáticos, investe-se também na construção de gasodutos e oleodutos na XUAR. Ao longo do século XXI, a preocupação com a segurança energética tornou-se central em qualquer planejamento, pois os riscos de paralisia da economia ou de violações da soberania dependem do acesso aos recursos energéticos. Nesse sentido, a China tem buscado diversificar seu abastecimento, escapando a qualquer forma de dependência, sobretudo de regiões instáveis como o Oriente Médio. Da mesma forma, o governo chinês busca diminuir a dependência do Estreito de Malaca como rota de abastecimento, região por onde passa cerca de $80 \%$ do suprimento do país (YIWEI, 2016). Com a Nova Rota da Seda e a facilitação do acesso à Ásia Central, a China tende a diversificar os fornecedores de energia, recursos minerais e alimentos. Isto permitirá que o país acesse os suprimentos energéticos vindos tanto do Oriente Médio quanto da Ásia Central, garantindo vitalidade aos seus índices de crescimento econômico (BRUGIER, 2014; FALLON, 2015). 
Figura 4 - Principais recursos naturais de Xinjiang e da Ásia Central

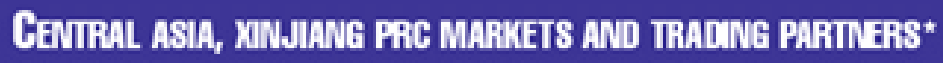

\begin{tabular}{|c|c|c|c|c|c|c|}
\hline Country/region & $\begin{array}{l}\text { Principal } \\
\text { natural } \\
\text { rosources }\end{array}$ & $\begin{array}{l}\text { Primary } \\
\text { farm products } \\
\text { and industrios }\end{array}$ & Major exports & Malor imports & $\begin{array}{l}\quad \text { Major trading } \\
\text { Formor } \\
\text { Sovist Union }\end{array}$ & $\begin{array}{l}\text { partners } \\
\text { Other }\end{array}$ \\
\hline Kazakhstan & $\begin{array}{l}\text { Oll and gas, chrome, } \\
\text { iron ore, coal, goid, } \\
\text { copper, lead-zinc } \\
\text { ore, tungsten }\end{array}$ & $\begin{array}{l}\text { Wheat, barley, meat, } \\
\text { wool, metalurgy. } \\
\text { textiles, machine } \\
\text { buliding, } \\
\text { petrochemicals }\end{array}$ & $\begin{array}{l}\text { Oll and gas, coal, } \\
\text { nonferrous metaliurgy. } \\
\text { grain, garments, } \\
\text { footware }\end{array}$ & $\begin{array}{l}\text { Machinery, oll } \\
\text { and gas, } \\
\text { processed food } \\
\text { and beverage, } \\
\text { ferrous metalirgy }\end{array}$ & $\begin{array}{l}\text { Russia, Ukraine, } \\
\text { Uzbekistan, } \\
\text { Kyrgyzstan }\end{array}$ & $\begin{array}{l}\text { China, } \\
\text { Germany. } \\
\text { \$weden, } \\
\text { Switzerland }\end{array}$ \\
\hline Kyrgyz Republic & $\begin{array}{l}\text { Hydroelectricity, } \\
\text { gold, mercury, } \\
\text { uranium, coal, } \\
\text { ceslum, antimiony }\end{array}$ & $\begin{array}{l}\text { Tobacoo, livestock, } \\
\text { wool, metallurgy. } \\
\text { agro-processing. } \\
\text { electronics, } \\
\text { textles, sugar }\end{array}$ & $\begin{array}{l}\text { Agro-machinsry. } \\
\text { wool, tobacco } \\
\text { products }\end{array}$ & $\begin{array}{l}\text { OI and gas, whoat } \\
\text { processed food, } \\
\text { machinery, chemicals, } \\
\text { light industrial } \\
\text { products }\end{array}$ & $\begin{array}{l}\text { Russia, Ukraine, } \\
\text { Kazakhistan, } \\
\text { Uzbekistan }\end{array}$ & $\begin{array}{l}\text { Germary, Bulgaria, } \\
\text { Czech \& } \\
\text { Slovak Republics, } \\
\text { China }\end{array}$ \\
\hline Uzbekistan & $\begin{array}{l}\text { Oll and gas, gold, } \\
\text { coal, sitwer, copper, } \\
\text { lead-zinc ore, } \\
\text { tungsten }\end{array}$ & $\begin{array}{l}\text { Cotton, muts and } \\
\text { vegetables, textiles, } \\
\text { coltion harvosters, } \\
\text { textile machinery. } \\
\text { metallurgy }\end{array}$ & $\begin{array}{l}\text { Cotton, gold, gas, } \\
\text { fertilizers, light } \\
\text { indestrial } \\
\text { goods }\end{array}$ & $\begin{array}{l}\text { Machinery, } \\
\text { oll and gas, } \\
\text { chemicals }\end{array}$ & $\begin{array}{l}\text { Russia, Ukraine, } \\
\text { Kazzakhstan, } \\
\text { Kyrgyzstan }\end{array}$ & $\begin{array}{l}\text { Switzerland, } \\
\text { South Korea, } \\
\text { Turkey, China }\end{array}$ \\
\hline Xinjlang PRC & $\begin{array}{l}\text { Oll and gas, } \\
\text { coal, gold, } \\
\text { cotton, grapes }\end{array}$ & $\begin{array}{l}\text { Cottion, corn, } \\
\text { sugar beet, } \\
\text { animal husbandry, } \\
\text { minerals extracton, } \\
\text { petrochemicals, } \\
\text { textiles }\end{array}$ & $\begin{array}{l}\text { Sugar, maze, } \\
\text { tomato ketchup, } \\
\text { pears, hops, } \\
\text { cotton, sheep's } \\
\text { casings, wool, } \\
\text { garments, carpets }\end{array}$ & $\begin{array}{l}\text { Steel products, } \\
\text { chemical raw } \\
\text { materials, fertlizers, } \\
\text { buliding materials }\end{array}$ & $\begin{array}{l}\text { Kazakhstan, } \\
\text { Uzbekistan, } \\
\text { Kyrgyzstan, } \\
\text { Pussla, } \\
\text { Ukraine }\end{array}$ & NA \\
\hline
\end{tabular}

"For perposes of this study, Central Asia resors to Uzbekistan, Kazakhstan, Kyrgyz Republic, and Xinjlang PRC.

Fonte: Central Asia (2017).

Deve-se ressaltar que Xinjiang é extremamente importante para a Nova Rota da Seda, não somente pelos recursos energéticos, como petróleo e gás, presentes no seu próprio território, mas também pela condição de espaço de conexão de todo tipo de infraestrutura. A XUAR tem sido objeto de uma grande expansão do comércio transfronteiriço entre diversos Estados asiáticos e a China (ELMER, 2011). Mas a questão de fundo ultrapassa a dimensão econômica, pois o oeste chinês é parte da reconstrução nacional, da integração regional e da projeção global da China. Em outras palavras, há um Novo Grande Jogo (RASHID, 2003) que passa por Xinjiang, na medida que desta região dependem a integração territorial chinesa e sua liderança sobre a integração regional impulsionada via OCX e Nova Rota da Seda. Não se deve esquecer que em um potencial cenário de ruptura do tráfego no Estreito de Malaca, os estrategistas chineses desenvolveram dois planos de contingência: o primeiro é a ligação do Paquistão (porto de Gwadar) até Xinjiang e o segundo a ligação de Mianmar (porto de Sittwe) até Yunnan. São, pois tanto vias de segurança energética, quanto de transporte de de bens (CARRIÇO, 2007, p.14). 
Figura 5 - Xinjiang e a integração da infraestrutura regional

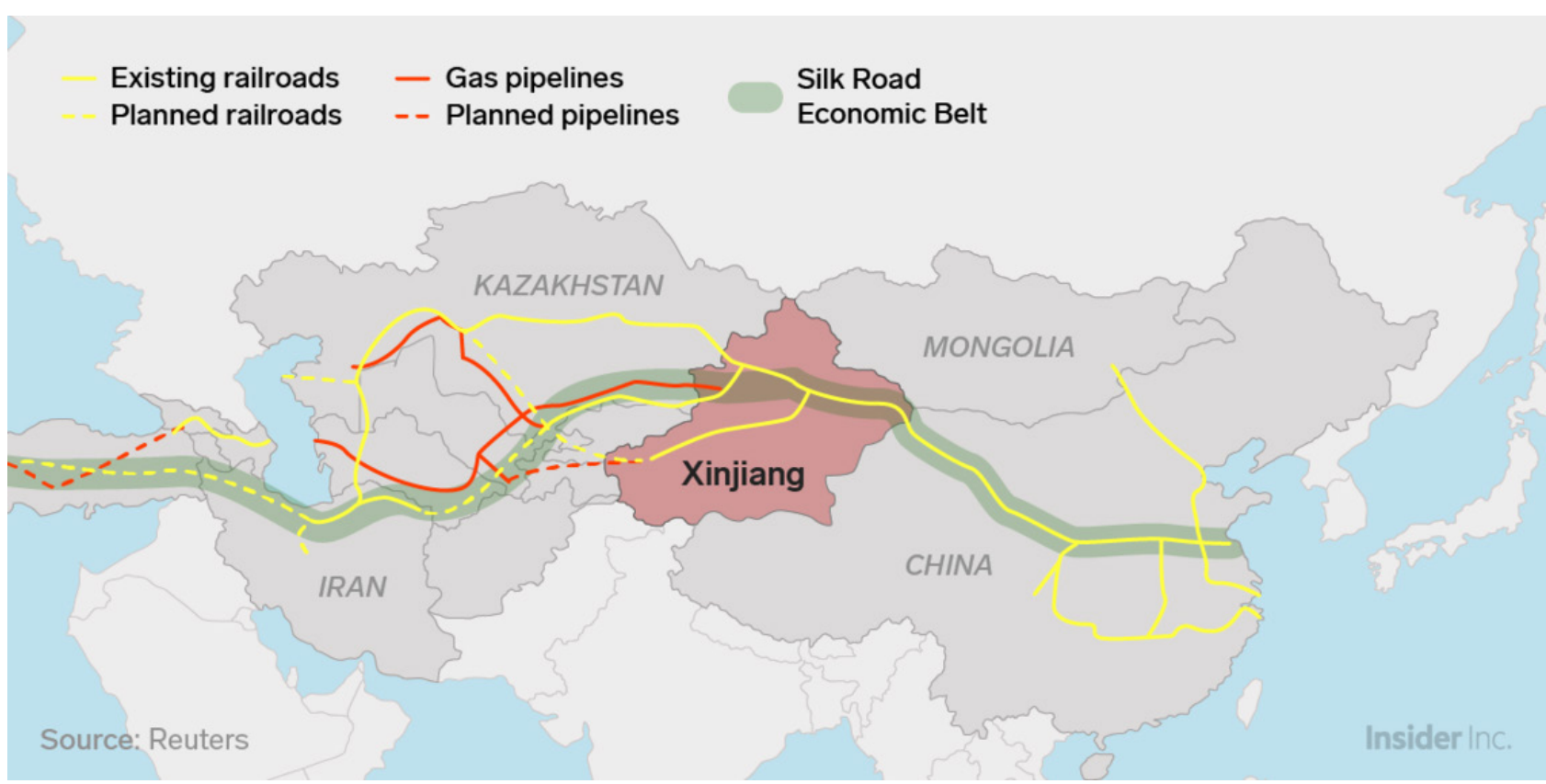

Fonte: Ma (2019).

Dada a complexidade do projeto, estas dimensões acabam se interconectando. No caso da ligação com o porto paquistanês, cabe indicar que a cidade de Gwadar está situada em zona paquistanesa também afetada pela atuação de movimentos separatistas, na província do Baluchistão, onde atua o Exército de Libertação do Baluchistão. Até 2007 o Paquistão possuía apenas dois portos comerciais, situados em Karachi e Bin Qasin. Ciente da vulnerabilidade de ambos frente aos possíveis ataques da Índia - que em 1971 alvejou o complexo portuário de Karachi com mísseis -, há décadas o Paquistão almejava a construção de um terceiro complexo, com profundidade territorial capaz de protegê-lo de eventuais movimentações indianas. Aliás, esta estratégia de estabelecer um "colar de pérolas" que se estenda desde a ilha de Hainan, que passa pelo arquipélago das Spratly, pelo Camboja, Tailândia, por Mianmar (ilhas Coco, ilha de Hainggyi, ilha Zadetkyi Kyun, portos de Sittwe, Kyaukpyu, Bassein, e Mergui), Sri Lanka e Bangladesh até à entrada do Golfo Pérsico (porto de Gwadar) tem vindo a suscitar preocupações aos estrategistas estadunidenses, indianos e iranianos (CARRIÇO, 2007).

Para lidar com esse cenário de instabilidade da região e da possibilidade de internacionalização do conflito, o governo chinês formatou diversas estratégias. A promoção da migração de população han para o oeste chinês constitui, nesse sentido, importante pilar de diluição da capacidade dos grupos extremistas islâmicos ampliarem seus laços com a população (DILLON, 2011), ainda que a imposição da população han nos negócios regionais - principalmente na gestão das atividades agrícolas e no acesso aos cargos públicos - tenha ampliado, de certa forma, o descontentamento com o governo chinês por substancial parcela da população originária da região (HAYES, 2015; TEDESCHI, 2015).

Por outro lado, o impulsionamento da interiorização do projeto de desenvolvimento chinês, preocupação enfatizada desde a elaboração 
do projeto Grande Desenvolvimento do Oeste, tem visado a diminuição das desigualdades regionais e a maior integração da economia nacional. Ademais, o contexto de cooperação da China com o Paquistão potencializou a importância de Xinjiang no conjunto do projeto de desenvolvimento chinês. O Corredor Econômico China-Paquistão é demarcado por uma vasta rede de infraestrutura, de cerca de $3.000 \mathrm{~km}$ de extensão, indo desde o porto de águas profundas no Mar da Arábia, em Gwadar, no Paquistão, até a cidade de Kashgar, na província de Xinjiang. Além de contribuir para dirimir as instabilidades securitárias do país vizinho, sua implementação corrobora os esforços chineses para evitar eventual check point estratégico no Estreito de Malaca. Por fim, o robustecimento da OCX - tendo como prioridade securitária o combate aos três males (terrorismo, separatismo e fundamentalismo) - permite a multilateralização do combate aos grupos extremistas locais.

Em suma, pode-se dizer que as questões securitárias de Xinjiang apresentam uma dimensão multifacetada dos desafios do governo chinês em âmbitos nacional, regional e até global. E, como destacou Mackerras (2015), ainda que as potências ocidentais sigam manobrando o discurso em prol da defesa dos direitos humanos na região, questionando as medidas de contenção ao terrorismo do PCCh, dificilmente o priorizarão diante das oportunidades econômicas que progressivamente surgem em Xinjiang, como fruto da execução dos vigorosos projetos de infraestrutura em curso. Dessa forma, cabe avaliar como a Nova Rota da Seda, como grande estratégia de inserção internacional da China, interage com a capacidade do país lidar com o desenvolvimento, a integração e a estabilização securitária da porção oeste de seu território, ao passo que impulsiona a ligação com a Ásia Central e demais regiões cruciais para o êxito das pretensões do gigante asiático.

Considerações finais

Xinjiang é uma região estratégica, e o governo chinês reconhece o imperativo de superar muitas clivagens sociais, regionais e étnico-religiosas ali existentes, inclusive a eliminação da pobreza extrema. Trata-se de um território crucial para a unidade nacional de um país multiétnico, bem como para continentalização do desenvolvimento chinês. É o espaço de enlace territorial do comércio e da integração regional com vários países vizinhos, sem o qual a OCX ficaria comprometida. Essa província é também rota infraestrutural essencial para a segurança do suprimento de recursos naturais, alimentos e energia para a economia chinesa.

Por toda sua importância, Xinjiang está no epicentro de dilemas securitários chineses. O transbordamento dos grupos terroristas e a aposta de Washington e seus aliados na desestabilização e desmembramento da China, torna a questão central para as autoridades chinesas. A guerra de informações promovida pelos Estados Unidos, pois, é parte de uma estratégia mais ampla de imposição de constrangimentos à projeção global da China. Tal estratégia de contenção inclui não apenas o fomento ao separatismo em Xinjiang, mas também no Tibete, em Taiwan e em Hong Kong, bem como o estímulo aos conflitos no Mar do Sul da China e a 
potencialização de posturas ideológicas anti-chinesas pelo mundo. Tudo isso ao passo em que os estadunidenses reforçam sua presença militar no Pacífico (Guam, Filipinas, Coreia do Sul, etc.), buscam sabotar a estabilidade política do sistema de governo chinês e recrudescem a Guerra Comercial. Isto é, a narrativa anti-chinesa sobre Xinjiang diz mais sobre os objetivos de Washington do que sobre as contradições étnicas-sociais-religiosas da China.

Parece, pois, que o futuro da região é decisivo para o desenrolar do processo da reconstrução nacional da China, iniciado em 1949, para a reconfiguração do sistema sinocêntrico e para a confirmação da Nova Rota da Seda - esta última uma espécie de projeto chinês de globalização. E, indubitavelmente, o êxito da iniciativa chinesa tende a ser variável chave na encruzilhada sistêmica, em que colidem dinâmica globais distintas, lideradas por Washington e Pequim.

Referências

AMIN, Samir. Los desafíos de la mundialización. México: Siglo XXI, 1996.

BANDEIRA, Luiz Alberto Moniz. A Segunda Guerra Fria. Rio de Janeiro: Civilização Brasileira, 2013.

BANDEIRA, Luiz Alberto Moniz. A desordem mundial. Rio de Janeiro: Civilização Brasileira, 2016.

BERLIE, Jean (edited). China’s Globalization and the Belt and Road. Switzerland: Palgrave Macmillan, 2020, pp. 41-56.

BRUGIER, Camille. China’s way: the New Silk Road. Paris: European Union for Security Studies, 2014

CARRIÇO, M.A.G. Uma "pérola” perto de um mar de petróleo: a importância do porto de Gwadar para a China. Revista Militar, 2007. Disponível em: https://www.revistamilitar.pt/artigo/217. Acesso em 01 out. 2019.

CENTRAL ASIA. Xinjiang PRC markets and trading partners. Central Asia, 2017. Disponível em: http://images.pennwellnet.com/ogj/images/ogj2/96244901.gif. Acesso em: 17 ago. 2017.

CHEN, Xiangming; MARDEUSZ, Julia. China and Europe: reconnecting across a New Silk Road. The European Financial Review, 10 fev. 2015. Disponível em: https://www.europeanfinancialreview.com/china-and-europe-reconnecting-across-a-new-silk-road/. Acesso em: 23 set. 2020.

CHINA. Vision and actions on jointly building Silk Road Economic Belt and 21st-Century Maritime Silk Road. 2015. Disponível em: http://en.ndrc.gov.cn/newsrelease/201503/ t20150330_669367.html. Acesso em: 18 ago. 2017.

CHINA-BRITAIN BUSINESS COUNCIL - CBBC. One belt one road: a role for UK companies in developing China's new initiative, new opportunities in China and beyond. Londres, 2016. Disponível em: http://files.chinagoabroad.com/Public/uploads/v2/uploaded/attachments/1509/ OBOR-1-New-Opportunities-in-China-and-Beyond.pdf. Acesso em: 22 set. 2020.

CLARKE, Michael. Beijing's March West: opportunities and challenges for China's Eurasian pivot. Orbis, v. 60, n. 2, p. 296-313, 2016.

COCKBURN, Patrick. A origem do Estado Islâmico. São Paulo: Autonomia Literária, 2015.

DILLON, Michael. Death on the Silk Route: violence in Xinjiang. BBC News, Londres, 2011. Disponível em: www.bbc.com/news/world-asia-pacific-14384605. Acesso em: 18 ago. 2019.

ELMER, Franziska. Tibet and Xinjiang: Their fourfold value to China. Culture Mandala: The Bulletin of the Centre for East-West Cultural and Economic Studies. v. 9, n. 2, p. 1-14, set./dez. 2011.

FALLON, Theresa. The New Silk Road: Xi Jinping's grand strategy for Eurasia. American Foreign Policy Interests. v. 37, n. 3, p.140-147, 2015.

FEVRIER, Vincent. Security in Xinjiang Province and the threat of ISIS attacks in China. Newton Aycliffe: Global Intelligence, 2017. 
FULLER, Graham; STARR, Frederick. The Xinjiang Problem. Mariland: The Johns Hopkins University, 2003.

HAYES, Anna. The Silk Road revisited? Locating Xinjiang in the China Dream. Peer-reviewed Conference Paper East Asia Security Symposium and Conference, Beijing, 2015.

HAO, Yufan; LIU, Weihua. Xinjiang: increasing pain in the heart of China's borderland. Journal of Contemporary China. v. 21, n. 74, p. 205-225, 2012.

HEGEL, G. W. F. Filosofia da História. Brasília: UnB, 1999.

LIANGQI, Lin. The strength of democracy: how will the CPC march ahead. Beijing: China Intercontinental Press, 2012.

LOSURDO, Domenico. Um mundo sem guerras. São Paulo: UNESP, 2018.

LOSURDO, Domenico. A não violência: uma história fora do mito. Rio de Janeiro: Revan, 2012.

MA, Alexander. This map shows a trillion-dollar reason why China is oppressing more than a million Muslims. Business Insider, 23 fev. 2019. Disponível em: https://www.businessinsider. $\mathrm{nl} / \mathrm{map}$-explains-china-crackdown-on-uighur-muslims-in-xinjiang-2019-2/. Acesso em: 23 set. 2020.

MERCATOR INSTITUTE FOR CHINA STUDIES. Mapping the Belt and Road initiative: this is where we stand. Mercator Institute for China Studies, 07 jun. 2018. Disponível em: https://merics.org/en/analysis/mapping-belt-and-road-initiative-where-we-stand. Acesso em: 23 set. 2020.

MILLWARD, James. Eurasian crossroads: a history of Xinjiang. New York: Columbia University Press, 2007.

PAUTASSO, Diego. A geografia do desenvolvimento da Ásia-Pacífico: as particularidades do caso chinês. Boletim Gaúcho de Geografia, v. 34, n. 1, p. 37-56, 2009.

PAUTASSO, Diego. UNGARETTI, Carlos. A Nova Rota da Seda e a recriação do sistema sinocêntrico. Estudos Internacionais. v. 4, n. 3, p. 25-44, 2017.

PINTO, Eduardo. O eixo sino-americano e as transformações do sistema mundial: tensões e complementaridades comerciais, produtivas e financeiras. In: LEÃO, Rodrigo; PINTO, Eduardo; ACIOLY, Luciana (Org.). A China na nova configuração global. Brasília: Ipea, 2011.

RASHID, Ahmed. Jihad. São Paulo: Cosac\&Naify, 2003.

REED, J. T.; RASCHKE, D. The ETIM: China's islamic militants and the global terrorist threat. Santa Barbara: Praeger, 2010.

TEDESCHI, Aline. Os Uigures em Xinjiang: autodeterminação ou terrorismo?. São Paulo: NEAI/IPRI/UNESP, 2015.

VISENTINI, Paulo Fagundes. Relações diplomáticas da Ásia. Belo Horizonte. Fino Traço, 2011.

VISENTINI, Paulo Fagundes. Ásia no Sistema Internacional: o primado neowestfaliano e as bases da multipolaridade. In: Encontro Nacional de Estudos Estratégicos, 2007, Brasília/DF. Anais. Brasília, DF: Presidência da República, Gabinete de Segurança Institucional, 2008.

WANG, Xinlin. Ideias e políticas para o desenvolvimento econômico do transporte de Xinjiang no contexto do Um Cinturão Uma Rota. Technology and Economic Guide, v. 28, n. 16, p. 172$173,2020$.

WEIHUA, Mao; JIA, Cui. Xinjiang to invest huge amount for highway network. China Daily, 2017. Disponível em: www.chinadaily.com.cn/china/2017-01/18/content_27984032.htm. Acesso em: 17 ago. 2017.

YAN, Hailong. The Silk Road Economic Belt, New Opportunities for the Opening-up and Development of Xinjiang. Economy and Management Publishing House, Beijing, 2016.

YIWEI, Wang. The Belt and Road Initiative: what will China offer the world in its rise. Beijing: New World Press, 2016.

YIWEI, Wang. China’s "New Silk Road”: a case study in EU-China relations. In: AMIGHINI, Alessia; BERKOFSKY, Axel (Ed.). ISPI Report Xi’s Policy Gambles: the Bumpy Road ahead. Milano: ISPI, 2015, p. 93-109.

ZHANG, Shaoying; MCGHEE, Derek. Social Policies and Ethnic Conflict in China. New York: Palgrave Macmillan, 2014. 